\title{
Los perjuicios en el contexto del artículo 18 de la Ley 256 de $1996^{1}$
}

\author{
EMilio José Archila Peñalosa²
}

\section{RESUMEN}

El presente escrito tiene el propósito de analizar los perjuicios que surgen de la conducta desleal que estipula el artículo 18 de la Ley 256 de 1996. Así, la tipificación que realiza esta norma contiene elementos que permiten identificar los casos en los cuales se indemnizará a los competidores afectados, lo cual se constituye como una sanción para quien ha tomado ventaja efectiva y significativa dentro del mercado por la violación de una norma. En consecuencia, resultará pertinente analizar los casos en los cuales se cumplen los requisitos de dicho enunciado normativo, ya que de él se desarrollan diferentes cuestionamientos respecto de la procedencia de las pretensiones indemnizatorias.

Palabras clave: Conducta desleal, daño, indemnización, competidores, mercado.

1 Fecha de recepción: 30 de octubre de 2016. Fecha de aprobación: 5 de noviembre de 2016. Para citar el artículo: Archila Peñalosa, E. (2016). Los perjuicios en el contexto del artículo 18 de la ley 256 de 1996, en Revista Con-Texto, n. ${ }^{\circ} 46$, pp. 11-24. DOI: https://doi.org/10.18601/01236458.n46.02 Ponencia elaborada en el marco del Seminario Violación de normas como conducta de competencia desleal - Artículo 18 de la Ley 256 de 1996 de la Universidad Externado de Colombia que se llevó a cabo el 11 de noviembre de 2016.

2 Abogado de la Universidad Externado de Colombia. Especialista en Legislación Financiera de la Universidad de los Andes. Magíster en Jurisprudencia Comparada (MCL) de New York University (NYU), School of Law, Nueva York, y en Derecho para el Desarrollo (DLC) del International Development Law Institute, Roma. Se ha desempeñado como director de la Oficina Jurídica del Ministerio de Desarrollo Económico, delegado para Seguros de la Superintendencia Bancaria de Colombia, delegado para la Promoción de la Competencia de la Superintendencia de Industria y Comercio, superintendente de Industria y Comercio y presidente de Asobolsa. Actualmente, es director del Departamento de Derecho Económico de la Universidad Externado de Colombia y consultor independiente en la firma Archila Abogados. Correo electrónico: earchila@uexternado.edu.co 


\section{DAMAGES IN THE CONTEXT OF ARTICLE 18 OF LAW 256/1996}

\section{ABSTRACT}

The present paper is directed to analyze the damages that arise from the unfair conduct stipulated in article 18 of the Law 256 of 1996. The qualification in this provision comprehends elements that allow us to identify the cases in which compensation would be granted to the affected competitors. Furthermore, it constitutes a sanction for those who have gained effective and significant advantage within the market by the violation of a law. Consequently, from a series of questions about the prosperity of the compensation claims, it becomes relevant to analyze in which cases the requirements of this provision are met.

Keywords: Unfair conduct, damage, compensation, competitors, infringement.

\section{INTRODUCCIÓN}

En el artículo 18 de la Ley 256 de 1996, el cual se encuentra en el capítulo de actos de competencia desleal, se señala lo siguiente: "[s]e considera desleal la efectiva realización en el mercado de una ventaja competitiva adquirida frente a los competidores mediante la infracción de una norma jurídica. La ventaja ha de ser significativa". El propósito de este acápite es analizar el daño indemnizable que surge de la infracción del artículo anteriormente mencionado.

La tesis que se pone en consideración analiza los perjuicios causados a un partícipe del mercado como consecuencia de la ventaja competitiva que otro interviniente en el mercado ha adquirido ilegalmente. Lo anterior excluye la posibilidad de examinar los perjuicios que se originan cuando un competidor viola una disposición legal.

En este entendimiento, la mera violación de una norma por parte de un competidor puede o no causar daño a otro competidor, dependiendo de que la disposición infringida consagre o no una prestación de uno a favor del otro. Así, si la norma señala una obligación de un competidor a favor del otro, el solo incumplimiento generará un daño en la víctima, consistente en haberse visto privado de lo que la ley previó en su favor. Mientras que en caso de que la norma no genere una prestación de un competidor a favor de otro, si el obligado incumple, ese incumplimiento no le causará, por esa sola circunstancia, un perjuicio a un competidor.

Además, esa clase de daño no es relevante frente a lo que estipula el artículo 18 de la ley citada. En efecto, la ley no previó como desleal la infracción de las normas. Por ello, lo anterior no quiere decir que en la primera hipótesis el competidor sea desleal y en la segunda no. No es correcto que el perjuicio de la primera alternativa sea el que se puede indemnizar a la luz del artículo 18, ni tampoco se puede concluir que en el segundo caso no habrá lugar a la deslealtad que estamos analizando. Lo que se previó es que sería desleal utilizar una ventaja competitiva adquirida mediante la violación de la ley. 
Por consiguiente, el perjuicio que es indemnizable al amparo del artículo 18 es el que se deriva del competidor-infractor que efectivamente utilizó una ventaja en su favor, que causo un desmedro a la víctima.

\section{FUENTES DE LAS OBLIGACIONES}

De acuerdo con el artículo 1494 del Código Civil, "[1]as obligaciones nacen, ya del concurso real de las voluntades de dos o más personas, como en los contratos o convenciones; ya de un hecho voluntario de la persona que se obliga, como en la aceptación de una herencia o legado y en todos los cuasicontratos; ya a consecuencia de un hecho que ha inferido injuria o daño a otra persona, como en los delitos; ya por disposición de la ley, como entre los padres y los hijos de familia" (subraya fuera de texto).

Así, la doctrina ha sido generosa en clasificaciones de las fuentes ${ }^{3}$. Sin embargo, para nuestros efectos, únicamente abordaremos (i) el contrato, (ii) la ley y (iii) el daño.

El contrato es "el concurso real de voluntades de dos o más personas encaminado a la creación de obligaciones. Esta fuente es un acto jurídico típico y caracterizado, puesto que sus efectos se producen en razón de la voluntad de los agentes ${ }^{\prime \prime}$. Respecto de la ley, se puede decir que "[e]l antecedente y el consecuente están previstos y sancionados por la norma, pero ella obra en virtud de un impulso, que es el hecho jurídico" ${ }^{\prime 5}$. Por su parte, el daño resarcible se constituye en fuente, partiendo de la base de que "quien perjudica a otro, en principio es llamado a reparar la ofensa"6, precisando que en ella se incorporan no solo los daños reparables que provengan de la culpa, por lo que esta categoría engloba en una sola figura todos los fenómenos indemnizatorios ${ }^{7}$.

Adicionalmente, el abuso del derecho ${ }^{8}$ es una especie del género daño resarcible. Según la Corte Constitucional" ${ }^{9}$, es "un ejercicio manifiestamente irrazonable o despro-

3 La determinación de las fuentes de las obligaciones presenta diferencias en la doctrina, en cuanto a su denominación y alcance: el profesor Hinestrosa refiere como fuentes el negocio jurídico, el daño resarcible, el enriquecimiento sin causa y los hechos jurídicos varios en donde analiza la ley. El tratadista Álvaro Pérez Vives refiere como fuentes los actos jurídicos, el enriquecimiento sin causa, la responsabilidad civil y la ley. Guillermo Ospina Fernández señala como fuentes el acto jurídico, donde se encuentran los contratos y actos unipersonales, y los hechos jurídicos, clasificados en hechos ilícitos y en el enriquecimiento sin causa.

4 Ospina Fernández, Guillermo. Régimen General de las Obligaciones. Bogotá D.C.: Editorial Temis, 2005, p. 39.

5 Hinestrosa, Fernando. Tratado de las Obligaciones II. De la fuente de las obligaciones: El negocio jurídico, t. I. Bogotá D.C.: Editorial Universidad Externado de Colombia, 2015, p. 68. Así mismo, indica que la ley se encuentra dentro de la fuente que denomina "hechos jurídicos varios legalmente reconocidos", bajo el entendido de que la ley actúa en virtud de un hecho jurídico.

6 Ibidem.

7 Ibidem, p. 67. La responsabilidad "no es la fuente de la obligación, es la consecuencia jurídica, eso es, la conclusión dentro de un proceso lógico desencadenado a partir del daño, o sea que la responsabilidad equivale a la obligación misma, y, por tanto, mal podría ser su fuente".

8 Constitución Política de Colombia, artículo 95.1.

9 Corte Constitucional. Sentencia C-090 de 2014. M. P. Mauricio González Cuervo. 
porcionado del derecho, contrario a las finalidades previstas por el ordenamiento para una disposición o institución jurídica"10. Entonces, abusa del derecho quien (i) ha adquirido el derecho legítimamente, pero lo utiliza para fines no queridos por el ordenamiento jurídico; (ii) se aprovecha de la interpretación de las normas, para fines o resultados incompatibles con el ordenamiento jurídico; (iii) hace un uso inapropiado e irrazonable de su derecho, a la luz de su contenido esencial y de sus fines; o (iv) invoca las normas de una forma excesiva y desproporcionada que desvirtúa el objetivo jurídico que persigue ${ }^{11}$.

En lo que hace al punto específico de este trabajo, nuestro entendimiento es que la competencia desleal es una forma particular de abuso del derecho. Es así como "los actos de competencia desleal se derivan ante un supuesto de responsabilidad extracontractual o aquiliana, en la que la obligación de indemnizar nace por la producción del evento dañoso al infringirse las normas impuestas, en este caso en el mercado y específicamente en la competencia"12. En estos casos, el condenado "debe responder por los daños sufridos por otro, con independencia de una relación prexistente entre responsable y víctima"13. Queda entonces claro, para comenzar, que el daño por indemnizar en los asuntos de competencia desleal deviene de un abuso del derecho, que se enmarca dentro la responsabilidad civil extracontractual y que, por tanto, su génesis no es la violación de la ley.

\section{CARACTERÍSTICAS DEL DAÑO INDEMNIZABLE}

Como lo explica la doctrina, "el ejercicio antifuncional de un derecho por parte de su titular resulta ilícito aun cuando no llegue a materializarse daño alguno al sujeto pasivo que se halla legitimado a reclamar la cesación del acto abusivo como prevención de los perjuicios que su continuación pudiera llegar a provocar, conforme la visión actual del derecho de daños, que contempla no solo la reparación de los daños ocasionados, sino la prevención de los que pudieron llegar a causarse $\mathrm{e}^{\prime 14}$.

Correctamente, la $\mathrm{SIC}^{15}$, haciendo referencia a fallos de la Corte Suprema de Justicia y el Consejo de Estado, ha indicado que "[i]ncumbe al demandante demostrar la

10 Al respecto, se tiene que "la valoración del abuso no sería de acuerdo con criterios subjetivos, sino que se haría con base en los criterios objetivos del estado general de las costumbres y de las relaciones sociales". Lo anterior, con base en la sentencia del 24 de marzo de 1939 proferida por la Sala Civil de la Corte Suprema de Justicia, en donde se señala, citando a COLIN y CAPITANT, que "los derechos pertenecientes a los particulares deben ejercerse sin exceso, según su destinación natural y de una manera normal, habida consideración del estado general de las costumbres y de las relaciones sociales". RENGIFO GARCíA, ERNESTO. Del abuso de derecho al abuso de la posición dominante. Bogotá D.C.: Editorial Universidad Externado de Colombia, 2002, p. 96.

11 Corte Constitucional. Sentencia C-258 de 2013. M. P. Jorge Ignacio Pretelt Chaljub.

12 Barona Vilar, Silvia. Competencia desleal, t. I. Valencia: Editorial Tirant Lo Branch, 2008, p. 806.

13 Visintini, Giovanna. ¿Qué es la responsabilidad civil? M. Cellurale (trad.). Bogotá D.C.: Editorial Universidad Externado de Colombia, 2015.

14 Ghersi, Carlos Alberto. Teoría general de la reparación de daños. Bogotá D.C.: Editorial Astrea - Universidad del Rosario, 2013, p. 254.

15 Superintendencia de Industria y Comercio. Sentencia 1495 del 19 de diciembre de 2011. 
existencia y cuantía del daño cuya reparación reclama, de modo que no le es dado a éste conformarse con probar simplemente el incumplimiento, por parte del demandado, de la obligación genérica o específica de que se trate, puesto que la infracción de la misma no lleva ineludiblemente consigo la producción de perjuicios ${ }^{16 "}$, respecto de lo cual "[e] s preciso que el juez tenga la certeza de que el demandante se habría encontrado en una situación mejor si el demandado no hubiera realizado el acto que se le reprocha"17.

En ese orden de ideas, el abuso del derecho, como conducta de competencia desleal, puede materializase en daños que resulten objeto de indemnización, como también es posible que dicha actuación infrinja una norma, pero no permita la procedencia del resarcimiento. Para ello, es necesario determinar si estamos ante un perjuicio indemnizable, validando la presencia de las condiciones propias de su existencia: cierto, personal y directo.

En los párrafos que siguen abordamos el tema, concretando las particularidades de cada aspecto a lo que toca al artículo 18 objeto de estudio:

\subsection{Certeza del daño}

\subsubsection{Concepto}

Se tiene que el daño será cierto ${ }^{18}$ "en la medida en que el juzgador conozca con evidencia que la acción dañosa ha producido o producirá desmedro patrimonial o moral en el perjudicado $^{\prime 19}$, cuya carga probatoria le corresponde a la víctima ${ }^{20}$. Ahora bien, para que surja la obligación indemnizatoria, existen dos hechos que no pueden confundirse: (i) el fenómeno que genera el daño y (ii) la actualidad del daño.

El fenómeno que genera el daño se refiere a los hechos "que desatan una cadena de mutaciones en el mundo exterior, cuyo efecto final va a ser la lesión a un bien patrimonial o extrapatrimonial de la víctima (...) debe existir y no puede ser futuro o eventual" ${ }^{\prime 2}$. En nuestro caso, el fenómeno generador de daño es la ventaja competitiva, la cual debe ser

16 Corte Suprema de Justicia, Sala de Casación Civil. Exp. 5860, julio 27 de 2001

17 Consejo de Estado, Sección Tercera. Exp. 10.479, mayo 21 de 1998.

18 Es decir, aquel que se opone a "aquel basado en suposiciones, conjeturas o meras expectativas". Corte Suprema de Justicia, Sala de Casación Civil. , 9 de julio de 2012. M. P. Ariel Salazar Ramírez.

19 Velásquez Posada, Obdulio. Responsabilidad civil extracontractual. Bogotá D.C.: Editorial Temis, 2015. En el mismo sentido, se tiene que la certeza del daño "aparece con evidencia que la acción lesiva del agente ha producido o producirá una disminución patrimonial o moral en el demandante". TAMAYO JARAMILLO, JAVIER. Tratado de responsabilidad civil, t. II. Bogotá D.C.: Editorial Legis, 2015, p. 339.

20 TAMAYO. Op. cit., p. 800. Este postulado se rompe, según lo refiere el autor, en casos reconocidos por la ley y la jurisprudencia colombianas donde la existencia del perjuicio es tan evidente que la ley libera a la víctima de probar la existencia del daño, como ocurre en los casos de lucro cesante por inmovilización de un capital (art. 1617 del C.C.), la depreciación monetaria, la presunción de daño en el contrato de transporte de mercancías (art. 1010 del C.C. y art. 1031 del C. CO.) y la presunción de daño en favor de los alimentarios de la víctima directa.

21 Ibidem. p. 348. 
significativa y estar siendo efectivamente usada en el mercado. Por otro lado, el daño actual no requiere ser constante, en tanto que puede ser pasado, presente o futuro ${ }^{22}$. Lo importante es que este resulte ser cierto $^{23}$. La Corte Suprema de Justicia ha indicado que "no solo el perjuicio actual es cierto, sino también el perjuicio futuro, pero no lo es el perjuicio simplemente hipotético. La jurisprudencia califica el perjuicio futuro de cierto y ordena repararlo, cuando su evaluación es inmediatamente posible, al mismo título que el perjuicio actual" ${ }^{\prime 24}$.

En este caso, la jurisprudencia de la SIC ha reiterado, en múltiples oportunidades, que el demandante tiene la carga de acreditar tanto la existencia del daño como la cuantía de la indemnización ${ }^{25}$. Además, se ha llegado a declarar la existencia del daño desestimando parcialmente pretensiones indemnizatorias; esto, porque el demandante "no atendió su carga probatoria (...) habiéndose realizado todos los esfuerzos encaminados a lograr la indemnización de la cuantía del daño"26. La misma Autoridad, abordando casos de participación en mercados sin el cumplimiento de los requisitos legales para ello, ha tenido dos aproximaciones. En un evento, ante la acreditación de que el demandado participó en el mercado sin pagar los costos y el precio que se precisaba para ingresar a la actividad, encontró competencia desleal y cuantificó los perjuicios, teniendo en cuenta la totalidad de los clientes que la empresa infractora había captado y los ingresos que estos le generaron ${ }^{27}$. Pero, en otra ocasión, concluyó que era adecuado indemnizar a la empresa demandante por la pérdida de la oportunidad ${ }^{28}$ de atender a los clientes que capturó la empresa "pirata"29.

Sin entrar en el análisis respecto de la manera como la SIC trató el punto del nexo causal en esos dos casos, que será objeto de estudio más adelante, lo cierto es que, conceptualmente, la posición del juez en este punto tiene sentido. Habiendo explicado lo

22 Se precisa que el daño futuro tiene la condición de cierto o efectivo, aun cuando sus "consecuencias se proyecten hacia adelante en el tiempo". Por ello, configurar el perjuicio indemnizable, a diferencia de lo que ocurre con el daño eventual, que carece del elemento fundamental de la certeza. El daño eventual "se opone, precisamente y en forma radical al concepto de certeza: daño eventual equivale, entonces, al daño que no es cierto; o sea, el daño meramente fundado en suposiciones o conjeturas". PEIRANO FACIO, JORGE. Responsabilidad extracontractual. Bogotá D.C.: Editorial Temis, 2004, pp. 370-372.

23 TAMAYO. Op .cit., p. 348.

24 Corte Suprema de Justicia, Sala de Casación Civil. Sentencia del 31 de mayo de 1998, Exp. 5023, y Sentencia del 11 de mayo de 1976, citadas por VeLÁSQUEZ. Op. cit., p. 271.

25 En todas las sentencias revisadas para la elaboración del presente documento, sin excepción, se exigen estas dos premisas.

26 Superintendencia de Industria y Comercio, Delegatura de Asuntos Jurisdiccionales. Sentencia del 10 de abril de 2013, Radicación: 120045568. Disponible en internet: https://vimeo.com/66362386

27 Superintendencia de Industria y Comercio, Delegatura de Asuntos Jurisdiccionales. Sentencia del 23 de julio de 2015, Radicación: 13-103452. Disponible en internet: https://vimeo.com/141903674

28 La pérdida de oportunidad es entendida como la pérdida de un beneficio esperado con ocasión la conducta desleal, en este caso, la violación de normas. Aquí, el demandante "está en una situación en la que el hecho del agente le impide tener la posibilidad que el azar el otorgue un beneficio". TAMAYO. Op. cit., p. 359.

29 A este respecto, Superintendencia de Industria y Comercio. Sentencia del 13 de diciembre de 2013, Radicación: 12-093040. Disponible en internet: https://vimeo.com/85941071 
anterior, debemos, antes de cerrar este acápite, analizar dos puntos relacionados con la certeza del daño en casos de competencia desleal por violación de normas, en lo relativo a las acciones preventivas y lo tocante a los fines concurrenciales.

\section{(a) Relativo a las acciones preventivas}

En el número 2 del artículo 20 de la Ley 256 de 1996, se facultó a "[1]a persona que piense que pueda resultar afectada por actos de competencia desleal" para "solicitarle al juez que evite la realización de una conducta desleal que aún no se ha perfeccionado, o que la prohíba aunque no se haya producido daño alguno". En la primera hipótesis, se accionaría para que no se haga uso de una ventaja competitiva significativa que se adquiriría en el mercado por la violación de una norma, pero, insisto, no se podría acudir a esta vía para, simplemente, evitar que se viole la ley ${ }^{30}$. Dado que en este caso la acción de competencia desleal no se ha materializado, no podrían existir perjuicios.

En la segunda hipótesis, deberán haberse llenado las dos condiciones de efectiva violación de la ley y, en especial, la de obtención consecuente de una ventaja competitiva significativa en el mercado sin que, hasta ese momento, ello haya causado un daño al demandante, razón por la cual la decisión sería la de prohibir el comportamiento. Nótese que, de nuevo, si solo se acredita la violación de la ley, no habrá competencia desleal y el juez no estará posibilitado para ordenar prohibición alguna.

\section{(b) Fines concurrenciales}

En el artículo 2 de la ley de competencia desleal se prevé que los comportamientos que se regulan serán desleales, siempre que se realicen en el mercado y que "... por las circunstancias en que se realiza, se revela objetivamente idóneo para mantener o incrementar la participación en el mercado de quien lo realiza o de un tercero". Por su parte, el artículo

30 Ibidem. A este respecto, la sentencia citada, en donde se declara la existencia del acto de violación de normas y desviación de clientela, sigue el criterio expuesto, en la medida que, aunque se refiere a la violación de normas de habilitación para la prestación de servicios de cirugía maxilofacial, la SIC explica que la ventaja competitiva significativa supone "un ahorro de costos que se traduce en la posibilidad de difundir en el mercado ofertas mucho más atractivas para los destinatarios de esas invitaciones"; así mismo, que el cumplimiento de la habilitación "supone que el prestador de servicios debe realizar una serie numerosa y costosa de gestiones encaminadas a tener una capacidad tecnológica, científica y técnico administrativa y una suficiencia patrimonial y financiera que le permita cumplir con los estándares previstos en la normativa aplicable. En ese sentido ingresar al mercado evadiendo el cumplimiento de esas barreras de entrada coloca al competidor desleal en una posición de ventaja respecto de sus competidores, pues además del ahorro de costos para ofrecer el servicio de salud, se habilita para participar en un mercado en el que no tiene autorización para intervenir y además lo puede hacer en mejores condiciones que los competidores que han cumplido con los requisitos de acceso establecidos". Así mismo, señala que "como no tuvo que incurrir en los costos asociados al cumplimento de los requisitos de acceso a ese mercado, se habilitó para tener unas utilidades más beneficiosas que las que podría derivar un competidor que hubiera cumplido con esas barreras de entrada de acceso". 
18 que se analiza clarifica que es desleal "la efectiva realización en el mercado de una ventaja competitiva...".

En ese orden de ideas, para que exista esa competencia desleal, no será suficiente que se haya violado la ley, y tampoco lo será que la violación de la ley genere una ventaja. Se precisa que el acto desleal debe, efectivamente, hacer uso de esa ventaja en el mercado. Por lo tanto, si bien para cumplir con el supuesto objetivo es factible hacer un análisis abstracto sobre la idoneidad de la conducta para que el infractor mantenga o incremente su participación en el mercado, para efectos de que el "fenómeno que genera el daño" sea cierto y presente, no bastará la constatación de la violación de una norma e imaginar que eso pondría al demandado en una situación privilegiada sobre su competidor, sino que esta ya tiene que haberse materializado.

\subsection{Carácter personal del daño}

Esta característica materializa el principio general, en virtud del cual, la indemnización puede ser reclamada por quien tiene legitimación para demandar la reparación del da$\tilde{n}^{31}{ }^{3}$, bajo el entendido de que "nadie puede enriquecerse a costa ajena, ni mucho menos pedir indemnización de un daño que no ha sufrido" ${ }^{\prime \prime 2}$.

El carácter personal del daño cuenta con un aspecto sustancial -la existencia del daño a esa persona-y otro procesal -la titularidad del derecho que se va a reclamar-, es decir, la identificación de la persona que puede demandar la reparación de lo que se sufriós ${ }^{33}$.

Para el caso de daños como resultado de acciones de competencia desleal por violación de normas, ese carácter personal lo tendrán, en acatamiento de lo redactado en el artículo 21 de la Ley 256, (i) cualquier persona que participe o demuestre su intención de participar en el mercado, cuyos intereses económicos resulten perjudicados por la efectiva realización en el mercado de una ventaja competitiva adquirida frente a los competidores mediante la infracción de una norma jurídica ${ }_{i}$ (ii) los miembros de asociaciones, cuando resulten gravemente afectados por la conducta (iii) los consumidores cuyos intereses resulten grave y directamente afectados. Sin embargo, el Procurador General de la Nación está legitimado para demandar; lo puede hacer cuando se afecte gravemente el interés público de conservar un orden económico y la libre competencia. En ese evento, creemos, no existirá alguien que pueda considerar que se ha afectado personalmente y, por ello, precisamente, no procederá la declaración de perjuicios.

De los casos analizados y referenciados a lo largo del presente documento, no encontramos evidencia explicita que haga alusión y explique en detalle este elemento

31 VELÁSQUEZ. Op. cit., p. 273. El autor señala que el carácter personal del daño "es un problema de legitimación en la causa, un problema procesal para saber quiénes pueden solicitar la reparación".

32 TAMAYO. Op. cit., p. 425.

33 VELÁSQUEZ. Op. cit., p. 277. "Es claro que la lesión de un derecho constituye una condición de existencia del daño, necesaria para que proceda la indemnización. La lesión del derecho es entonces un elemento para apreciar el perjuicio reparable, lo que lleva al juez a desestimar las pretensiones de la demanda pero no a proferir sentencia inhibitoria si no se ha probado la titularidad del derecho sustancial pretendido". 
de configuración. Los elementos analizados por la SIC se refieren, particularmente, a la existencia del daño y la prueba de la cuantía de la indemnización.

\section{NEXO CAUSAL}

En la aceptada acepción, el nexo causal hace referencia a la "necesidad de un ligamen de causa a efecto entre la acción humana y el daño" ${ }^{34}$, de lo que se entiende que "uno solo responde por los efectos de su propia conducta" ${ }^{135}$. Así, solo se debe responder por los daños directos, es decir, "aquellos que son consecuencia del hecho dañoso imputable al obligado a la reparación" ${ }^{\prime \prime}$, y no respecto de aquellos "donde no es posible establecer claramente un nexo causal entre la conducta del agente a quien se le intenta imputar el daño ${ }^{\prime \prime 37}$.

Ahora, en materia de competencia desleal, existirá perjuicio indemnizable cuando se establezca la existencia del acto de competencia desleal y el nexo causal de este con el daño sufrido ${ }^{38}$.

Bajando esa claridad al tema de este capítulo, tenemos que "[e]l común denominador de los actos que caen bajo este supuesto es que son estrategias competitivas que sólo son posibles por la infracción de normas jurídicas, esto es, el infractor utiliza la violación de la norma como un instrumento para obtener ventajas en la lucha concurrencial" ${ }^{\prime \prime}$. Esta circunstancia genera una particular dificultad, dada la necesidad de diferenciar los daños causados por la infracción legal, aquellos que pueden ocurrir cuando existe un contrato que se sustenta en la ley violada que a su vez es incumplido ${ }^{40}$, y los que nos interesan, que son los que se causan por el efectivo uso de una ventaja competitiva adquirida mediante la infracción de la ley.

Ahora bien, respecto de los actos desleales acontecidos por la demostración de la existencia de los supuestos previstos en el artículo 18 de la Ley 256 de 1996, el nexo causal debe acreditarse entre la utilización efectiva de la ventaja competitiva significativa y el daño, y no entre la violación de normas y algún daño. El anterior entendimiento deviene justamente de la configuración del acto consagrado en el artículo 18 de la Ley 256 de 1996. Allí, la violación de la ley es el medio para obtener la ventaja competitiva,

34 Peirano. Op. cit., p. 405

35 Tamayo Jaramillo, Javier. Tratado de responsabilidad civil, t. I. Bogotá D.C.: Legis, 2015, p. 248.

36 VELÁSQUEZ. Op. cit., p. 282.

37 Ibidem

38 BARONA. Op. cit., p. 812.

39 Kresalja Rosselló, Baldo. Lo que a mí no me está permitido hacer tampoco debe permitírsete a ti (apuntes sobre el acto desleal por violación de normas), en Themis - revista de derecho, n. ${ }^{\circ}$ 50, 2005, p.15.

40 Otras formas de protección que pueden constituirse de la consecuencia de incumplimiento contractual: "La acción es procedente debido a que en el caso sub lite lo que se encuentra en discusión es si la conducta resultó contraria a los deberes de conducta contemplados de manera abstracta en la señalada ley, sin referencia a los efectos que dicha conducta pudo generar desde el punto de vista de las normas del contrato celebrado entre las partes de este proceso". Tribunal Superior de Bogotá, Sala Civil, 5 de agosto de 2003, y Superintendencia de Industria y Comercio, Resolución 509 de 2004. 
pero, por sí misma, no es una conducta desleal. Por lo tanto, el perjuicio indemnizable en el acto desleal analizado debe ser aquel fundado en el daño infringido con ocasión de la utilización de la ventaja adquirida por la violación de la norma, que resulta sustancialmente distinto al perjuicio que se origina por la violación de la norma.

Como ya se expresó, la fuente de la competencia desleal como un ejercicio abusivo del derecho es el daño; no es la ley ni, mucho menos, la violación "pura y simple" de esta. En las sentencias ya citadas de la SIC, proferidas el 13 de diciembre de 2013 en el expediente no. 12-093040 y el 23 de julio de 2015 en el proceso radicado con el número 13-103452, relacionadas con el incumplimiento de normas de habilitación para prestar servicios de telefonía y odontológicos, se evidencia claridad sobre la necesidad del nexo causal entre la ventaja competitiva significativa y el daño ${ }^{41}$.

En contravía con esa, en nuestra opinión, correcta interpretación, en otros casos, la misma SIC ha tomado decisiones en donde el nexo causal existe sólo entre la violación de normas y el daño.

En la sentencia proferida el 20 de junio de 2014 en el proceso radicado con el número 13-013416 ${ }^{[42]}$, la SIC declaró la existencia del acto de violación de normas. La empresa ' $X^{\prime}$ suministró combustible a $\mathrm{B}, \mathrm{C}$ y $\mathrm{D}$, sin que estas últimas tuviesen contratos con ' $\mathrm{X}$ '. Por el contrario, 'B', 'C' y 'D' tenían contratos con la empresa ' $Y^{\prime}$, demandante. La sentencia refiere que la empresa X vulneró el artículo 15.9 del Decreto 4299 de 2005, según el cual es obligación de los distribuidores mayoristas de combustibles "[a]bstenerse de vender combustibles líquidos derivados del petróleo a distribuidores minoristas con los cuales no se tenga un contrato y consecuentemente, no tengan exhibida su marca comercial". La SIC se pronunció respecto de los perjuicios y tuvo en cuenta que "[c]on relación a la existencia del daño está acreditado que ' $Y$ ' dejó de percibir una serie de ingresos si no hubiera acontecido la violación, si hubiera mantenido los contratos, es claro para el despacho que existió un daño por violación de normas". Respecto de la cuantificación, alude a que "[e]l perjuicio debe ser cierto y directo, es incuestionable colegir que ' $\mathrm{Y}$ ' hubiese podido percibir unos ingresos que estaban asociados a las formas de cada vinculación con los propietarios del servicio". Para tal efecto, se apoya en una prueba pericial que da cuenta de lo que la empresa ' $\mathrm{Y}^{\prime}$ dejó de percibir respecto de los contratos de suministro con las empresas ' $\mathrm{B}^{\prime}, \mathrm{C}^{\prime} \mathrm{y}{ }^{\prime} \mathrm{D}^{\prime}$.

Llama la atención que al analizar la pretensión indemnizatoria respecto de la conducta de inducción a la ruptura contractual, refiere que "[n]o es posible indemnizar dos

41 Sin entrar a analizar el alcance del concepto que ofrece la SIC en torno a la ventaja competitiva y la significatividad, podemos afirmar que en tales decisiones, la SIC sustenta la existencia de una ventaja competitiva para las demandadas, en tanto que no incurrieron en los costos y trámites que implica el cumplimiento de los requisitos para la habilitación legal, hecho que les permite participar en un mercado donde no debían hacer presencia, y ofrecer unas condiciones de precio más favorables para los consumidores, lo que genera un daño en el patrimonio de las demandantes. Aquí, la violación de la norma se constituye en el medio para adquirir una ventaja competitiva significativa que termina por generar el daño en las demandantes.

42 Sentencia disponible en internet: https://vimeo.com/104743898 
veces una misma situación fáctica ni un mismo perjuicio, resulta pertinente colegir no obstante la declaración de este acto desleal, la indemnización está cubierta con la del artículo 18". Si bien compartimos dicha conclusión, respetuosamente discrepamos de su sustento. En aquellos casos donde se induce a la ruptura contractual, el perjuicio puede estar asociado a los ingresos que se dejaron de percibir, justamente, por la ocurrencia de dicha conducta desleal. No obstante, en el caso del acto desleal de violación de normas, debió analizarse si los hechos acaecidos generaron o no una ventaja competitiva significativa, y si esta ventaja fue utilizada en el mercado y generó perjuicios. El nexo causal debió establecerse entre el uso de la ventaja y el daño generado por el uso de la ventaja, el cual no se traduce en lo dejado de percibir por el contrato.

Con ello, nuevamente se tiene que si se viola una norma y esa violación implica la ocurrencia, como en este caso, de otro acto desleal, no por ello se configura el acto previsto en el artículo 18 de la Ley 256 de 1996, es decir, existiría la violación de una norma, pero no el acto desleal de violación de normas. En la sentencia proferida el 8 de noviembre de 2013, con radicación 2012-217369 ${ }^{[43]}$, la SIC declaró la existencia de los actos de competencia desleal de confusión, imitación y violación de normas. En el caso, declara la existencia del acto de violación de normas, en tanto se demuestra que la demandada violó normas de derecho de autor ${ }^{44}$ y que existió una ventaja competitiva significativa que "[c]onsistió en la posibilidad de comercializar un producto sin incurrir en los costos inherentes para la obtención de las autorizaciones necesarias para usar esas obras". Así mismo, señala que "[1]a demandada materializó esa ventaja competitiva significativa transfiriendo ese ahorro en un menor precio al consumidor".

Para efectos indemnizatorios, tiene en cuenta como lucro cesante los ingresos que dejó de percibir la demandante por las ventas de los productos realizadas por la demandada, partiendo de la base de que "[s]i el único autorizado para la venta era el demandante, cualquier venta del producto corresponde a una venta no realizada por el demandante", y los ingresos que dejó de percibir la demandante, "que habían correspondido a la necesaria contraprestación que habría tenido que reconocer la demandada para poder comercializar los productos que reproducen las creaciones intelectuales de la demandante". Respecto del quantum, adoptó el formulado como juramento estimatorio en el texto de la demanda, en tanto que no fue objetado por la parte demandante, con fundamento en el artículo 206 del CGP.

En este caso, nuevamente se establece el nexo causal entre la violación de la norma y la consecuencia misma de dicha violación, sin tener en cuenta el que efectivamente debería analizarse, que es el que se predica de la utilización de la ventaja competitiva significativa y el daño generado por tal conducta. Aquí se analiza el daño que produce en el demandante la violación pura y simple de la norma, para efecto de configurar el acto desleal y, con base en ella, acceder a la pretensión indemnizatoria. 
Nuevamente se equivoca la SIC, en nuestro criterio, en la sentencia con n ${ }^{\circ} 120045568$ del 10 de abril de $2013^{[45]}$. En este caso, la SIC declara la violación de las normas referidas a la portabilidad numérica ${ }^{46}$, respecto del rechazo de solicitudes de portación sin fundamento legal. En cuanto a los perjuicios, indica que se constituyen "[e]n el lucro cesante derivado de la violación normativa en la que incurrió $\mathrm{X}^{\text {"; }}$ alude que "[e]1 daño se acreditó debidamente, porque el dictamen pericial acreditó claramente que el comportamiento de $\mathrm{X}$ privó a Y de los ingresos derivados de los usuarios que habían solicitado su portación a $\mathrm{X}$ y que $\mathrm{X}$ impidió ilegítimamente" 47 .

En este caso, llamamos la atención en dos aspectos: el primero, que la sentencia alude a que la ventaja significativa no se determina por el impacto de la deslealtad en el competidor $^{48}$. Para efectos indemnizatorios, y en atención al elemento causa - efecto, consideramos que "el impacto" resulta fundamental, en tanto que este elemento refiere la afectación de la operación del demandante con ocasión de la utilización de la ventaja competitiva. En consonancia con lo referido en los demás casos que, respetuosamente, no compartimos, el nexo causal se presenta entre la violación de la norma y el daño sufrido por el demandante, que obedece al mero incumplimiento de la ley, y no en el acto desleal de violación de normas.

Un escenario extremo de la confusión sobre el nexo causal en casos de violación de normas lo encontramos en eventos de prestaciones mutuas originadas en la ley. Con ellas, nos referimos a aquellos asuntos en los cuales la SIC ordena la indemnización por daños y perjuicios, a partir del no cumplimiento de la prestación que contiene la norma a favor del demandante.

En estos casos, la norma violada a partir de la cual se configura el acto desleal de violación de normas (sin perder de vista que todos los elementos de la conducta deben estar demostrados) contiene prestaciones para demandante y demandado, y es justo el primero el que, mediante la acción de competencia desleal, exige, no los perjuicios que se causan por la utilización de una ventaja competitiva, sino el pago de, precisamente, la prestación que contempla la norma a su favor.

45 Disponible en internet: https://vimeo.com/66362386

46 Ley 1245 de 2008.

47 Un análisis similar, sustentado en la violación de normas de portabilidad numérica, se encentra en la Sentencia del 30 de abril de 2013, Radicación: 1 2095354. Disponible en internet: https://vimeo. com/66362389

48 En la sentencia, se explica el elemento significativo, refiriendo que "[1]a base que la ventaja debe tener una intensidad significativa desde el punto de vista concurrencial. Este carácter significativo, significa (sic) que debe jugar un cierto papel en la decisión de esa alternativa de mercado y que en la mayoría de los casos, supondrá un ahorro de costos que deberá traducirse en la oferta que formula el infractor. Aquí hay un aspecto importante para resaltar y es que el carácter significativo de la ventaja no se determina por el impacto que la conducta desleal pueda causarle al competidor que es víctima de ese comportamiento, el carácter significativo deviene de la existencia de una situación que genere al competidor desleal, una condición favorable de magnitud importante en el desarrollo de su actividad mercantil". 
Revisando las decisiones jurisdiccionales de la SIC desde el año 2012 ${ }^{[49]}$ en las cuales declaró la existencia de la conducta de violación de normas, encontramos ejemplo de esta modalidad en las sentencias proferidas el 26 de mayo de 2016 en los expedientes 2015-47764 y 2015-44442. Los casos hacen referencia a la violación de normas relacionadas con cargos asimétricos en telefonía móvil celular ${ }^{50}$, la cual se concretó en que la demandada "vulneró unas normas que se encontraban vigentes relacionadas con la regulación justamente del valor de cargos, por la retribución que los operadores de la telefonía móvil tienen entre sí, por la interconexión de sus redes".

En cuanto a la ventaja competitiva y su significatividad, señala la SIC que "[s]e encuentran también acreditados, para esto se debe decir que la existencia de la ventaja competitiva, parte de la misma regulación de la CRC, en tanto que desde la resolución 4002, la CRC a partir de la posición que tiene ese operador en el mercado de voz saliente móvil, constató la presencia de una falla en el mercado a favor de X y en contra de los demás operadores, por lo cual si X pudiera pagar los mismos valores que los demás operadores con ocasión de los cargos de acceso, la falla del mercado que se pretende corregir se mantendría y el mercado continuaría con ella representando así una desventaja para los demás proveedores del servicio de telefonía móvil".

Sin embargo, cuando llega al punto del nexo causal entre esa supuesta infracción y algún daño, señala que el perjuicio sería el "[m]ayor valor cobrado por X como cargo de acceso por la terminación del tráfico móvil en su red", respecto del cual, sin mayor análisis, concluye que las medidas cautelares decretadas anticiparon materialmente el fallo, en tanto que la demandada pagó las diferencias existentes. Así, el ejercicio que realiza la SIC determina un nexo entre el valor pagado de más por la demandante y la infracción de la disposición, sin reparar en que ese es un daño por infringir la ley y que, si lo hubiera habido, el nexo relevante para el artículo 18 es entre un daño y la efectiva utilización de una ventaja competitiva.

\section{BIBLIOGRAFÍA}

Alessandri, A. Teoría de las Obligaciones. Santiago de Chile: Imprenta el Esfuerzo, 1934.

Barona, S. Competencia desleal, t. I. Valencia: Tirant Lo Branch, 2008.

Corte Constitucional, Sentencia C-336 de 2012.

Corte Constitucional, Sentencia C-157 de 2013.

Corte Constitucional, Sentencia C-258 de 2013.

Corte Constitucional, Sentencia C-090 de 2014.

HENAO, J. El daño. Análisis comparativo de la responsabilidad extracontractual del Estado en derecho colombiano y francés. Bogotá D.C.: Universidad Externado de Colombia, 1998.

Hinestrosa, F. Tratado de las obligaciones II. De la fuente de las obligaciones: el negocio jurídico, t. I. Bogotá D.C.: Universidad Externado de Colombia, 2015. 
KRESALJA, B. Lo que a mí no me está permitido hacer tampoco debe permitírsete a ti (apuntes sobre el acto desleal por violación de normas), en Themis Revista de Derecho, 2005.

MASAGER, J. Comentarios de la ley de competencia desleal. Madrid: Cívicas, 1999.

Ospina, G. Régimen general de las obligaciones. Bogotá D.C.: Temis, 2005.

PeIRANO, J. Responsabilidad extracontractual. Bogotá D.C.: Temis, 2004.

RENGIFO, E. Del abuso del derecho al abuso de la posición dominante. Bogotá D.C.: Universidad Externado de Colombia, 2002.

Superintendencia de Industria y Comercio, Resolución 509 de 2004.

Superintendencia de Industria y Comercio, Sentencia 1495 de 2011.

Superintendencia de Industria y Comercio, Sentencia 173 de 2012.

Superintendencia de Industria y Comercio, Sentencia 616 de 2012.

Superintendencia de Industria y Comercio, Sentencia 823 de 2012.

Superintendencia de Industria y Comercio, Sentencia 824 de 2012.

Superintendencia de Industria y Comercio, Sentencia 840 de 2012.

Superintendencia de Industria y Comercio, Sentencia 12-0045568 de 2013. Acta 081. Disponible en internet: https://vimeo.com/66362386

Superintendencia de Industria y Comercio, Sentencia 12-093040 de 2013. Acta 387. Disponible en internet: https://vimeo.com/85941071

Superintendencia de Industria y Comercio, Sentencia 12-159369 de 2013. Acta 339. Disponible en internet: https://vimeo.com/85959639

Superintendencia de Industria y Comercio, Sentencia 12-095354 de 2013. Acta 103. Disponible en internet: https://vimeo.com/66362389

Superintendencia de Industria y Comercio, Sentencia 12-211504 de 2013. Acta 278. Disponible en internet: https://vimeo.com/85949725

Superintendencia de Industria y Comercio, Sentencia 13-103464 de 2013. Acta 396. Disponible en internet: https://vimeo.com/85951058

Superintendencia de Industria y Comercio, Sentencia 12-217369 de 2013. Acta 336. Disponible en internet: https://vimeo.com/85952613

Superintendencia de Industria y Comercio, Sentencia 13-136300 de 2014. Acta 098. Disponible en internet: https://vimeo.com/106287759

Superintendencia de Industria y Comercio, Sentencia 13-013416 de 2014. Acta 171. Disponible en internet: https://vimeo.com/104743898

Superintendencia de Industria y Comercio, Sentencia 13-103452 de 2015. Acta 196. Disponible en internet: https://vimeo.com/141903674

Superintendencia de Industria y Comercio, Sentencia 15-47764 de 2016.

Superintendencia de Industria y Comercio, Sentencia 15-44442 de 2016.

TAmayo, J. Tratado de la responsabilidad civil, t. I. Bogotá D.C.: Legis, 2015.

TAMAYO, J. Tratado de responsabilidad civil, t. II. Bogotá D.C.: Legis, 2015.

Tribunal Superior de Bogotá, Sala Civil (5 de agosto de 2003).

VeLÁSQUEZ, O. Responsabilidad civil extracontractual. Bogotá D.C.: Temis, 2015.

VISINTINI, G. ¿Qué es la responsabilidad civil? M. Cellurale (trad.). Bogotá D.C.: Universidad Externado de Colombia, 2015. 